كاربرد ماشين بردار يشتيبان در شبيهسازى الكوى رطوبتى تحت آبيارى قطرهاى

زينب حيدرى'، معصومه فراستى 'و ז* و رسول قباديان'

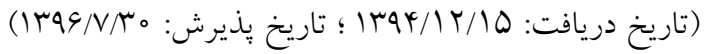

جكيده

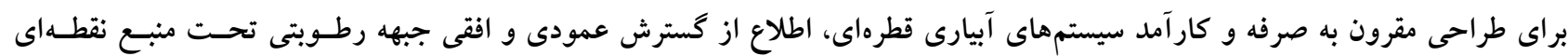

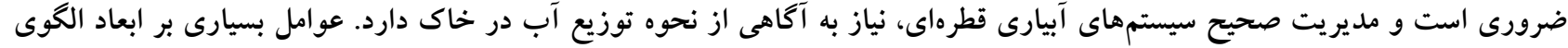

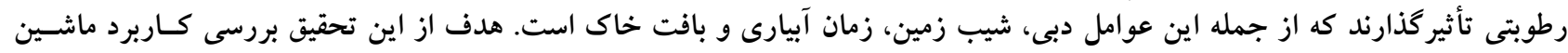

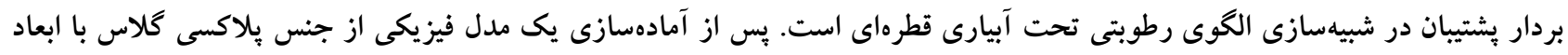

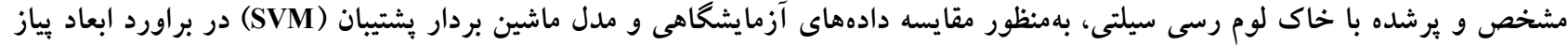

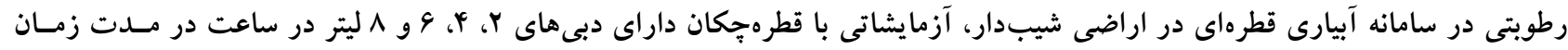

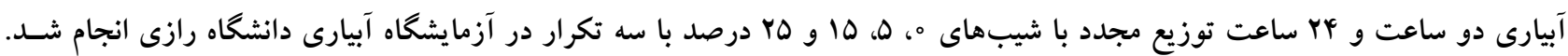

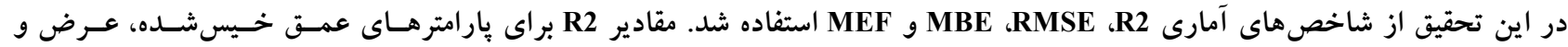

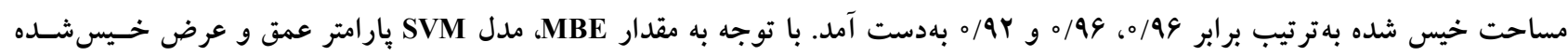

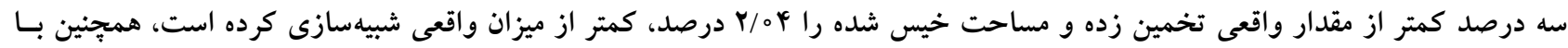

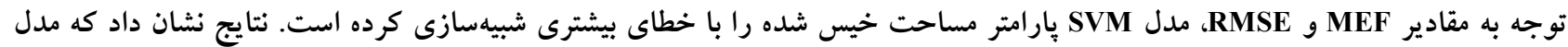

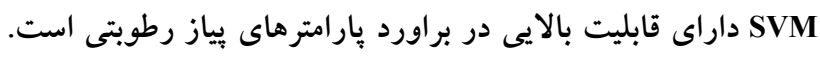

وازههاى كليدى: آبيارى قطرهاى، يياز رطوبتى، عمق خيس شده، عرض خيس شده، مساحت خيس شده 
مدل ساده براى براورد عمق و قطر يبـاز رطـوبتى بـا استفاده از

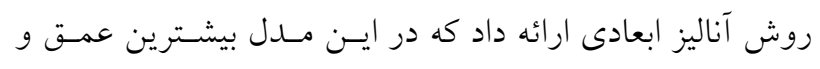

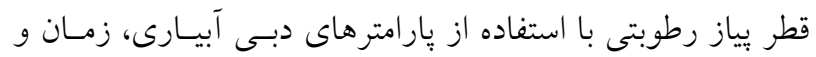

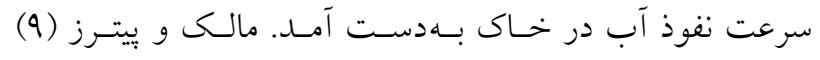
معادلهاى را با استفاده از دادههاى صحرايى و روش بهينهسـازى و رگرسيون غيرخطى بهدست آوردند كه اين مدل با استفاده از

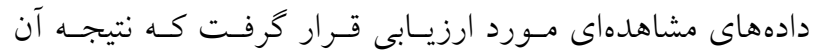

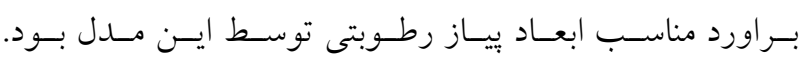

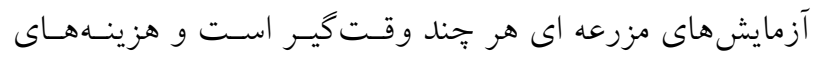

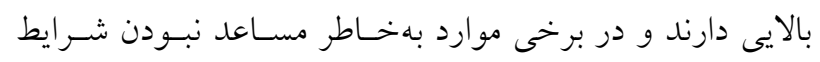

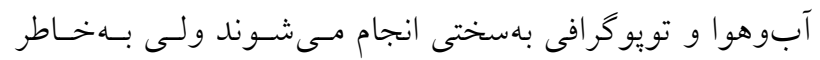

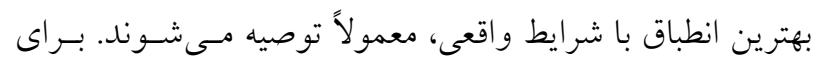

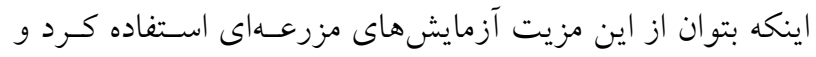

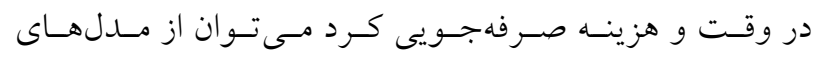
تخمين گر استفاده كرد. در اين راستا بـهكـاركيرى ماشـين بــردار

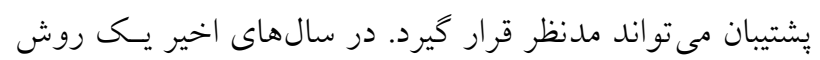

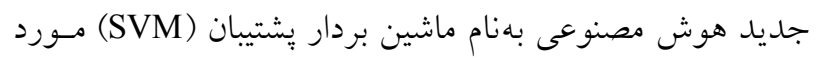

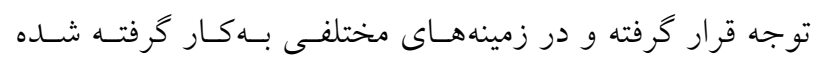

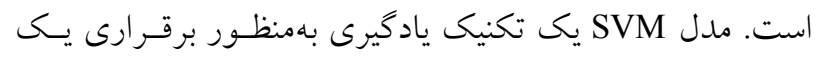
نحاشت بين ورودىها و خروجى است. ماشسين بـردار بشـتيبان

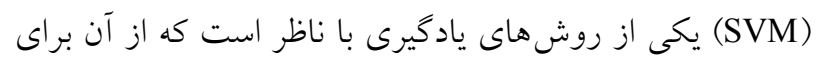

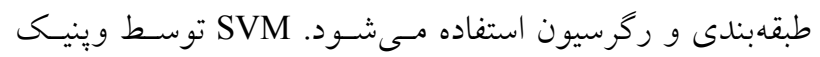

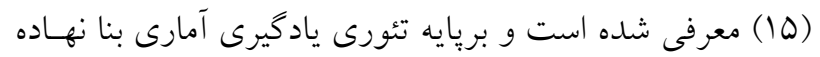

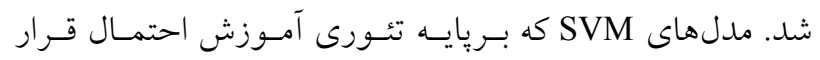

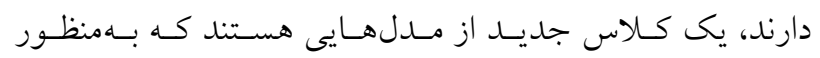

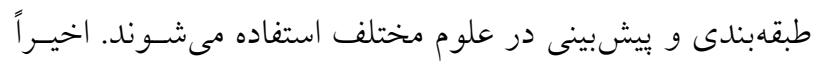

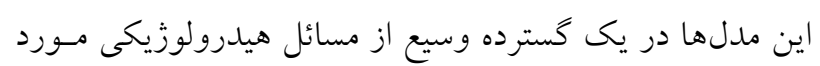

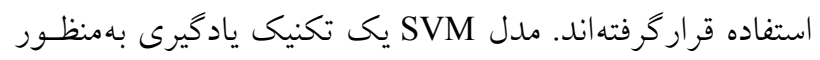
برقرارى يك نخاشت بين ورودىها و خروجى استـ. از SVM

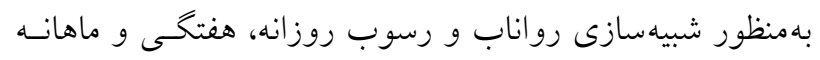
در هند استفاده شد (rا). نورى (1) با استفاده از SVM جريان

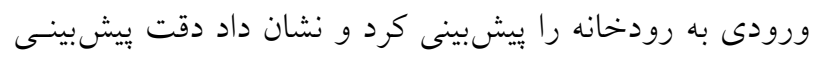

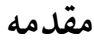

با توجه به كمبود بارندگى در كشورمان و اهميـت منـابع آب در

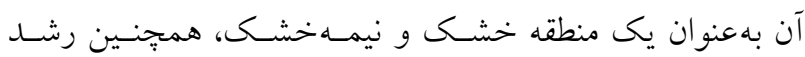

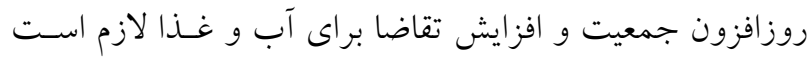

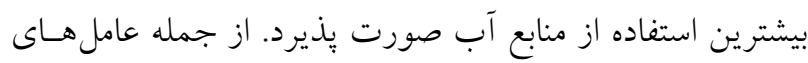

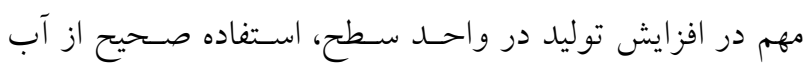

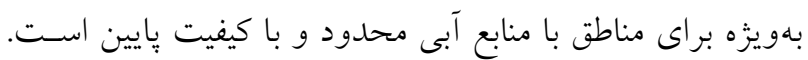

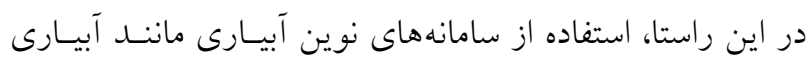

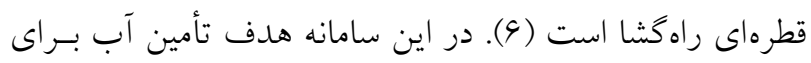

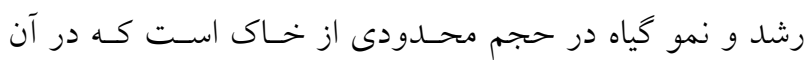

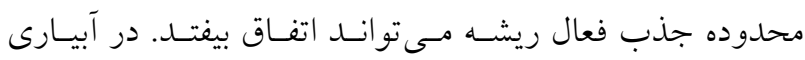

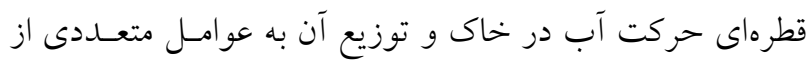

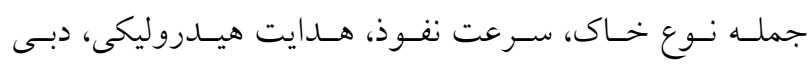

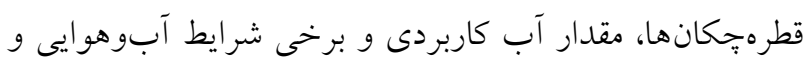
تويو گرافى زمين بستخى دارد.

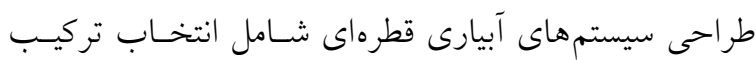

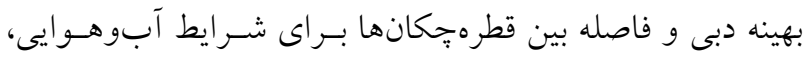

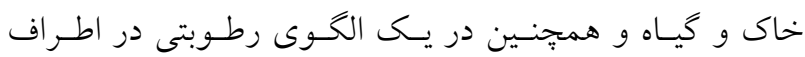

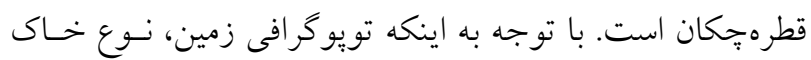

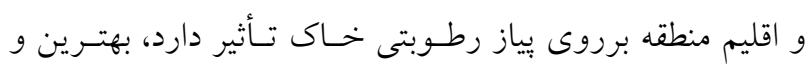

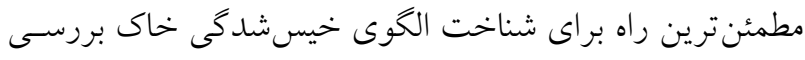

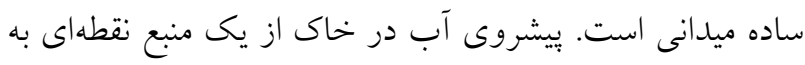

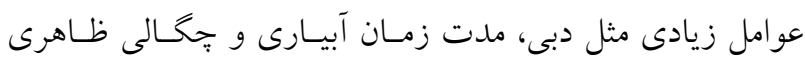

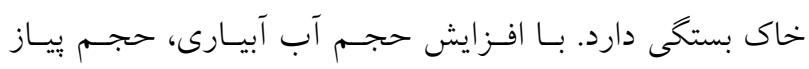

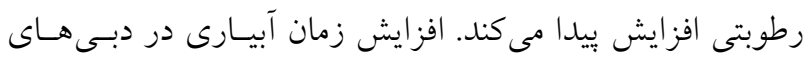

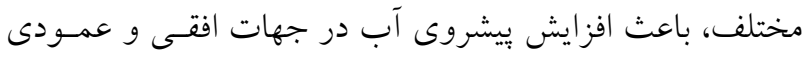
مىشود.

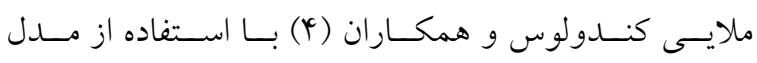
HYDRUS-2D كردند كه مقايسه دادههاى آزمايشـاهى و صـحر ايى بـا مقــادير شبيهسازى شده نشان از دقت خوب ايسن مــل در شـبيهسـازى

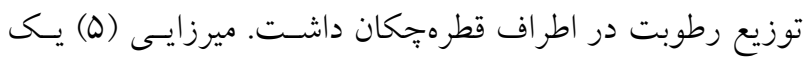


بهرهال مشابه با هر مدل رياضى و آمارى، مدلهاى SVM نيز

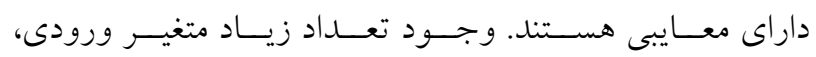

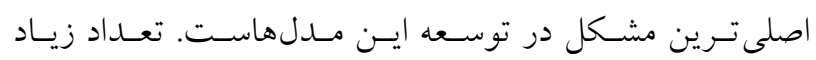

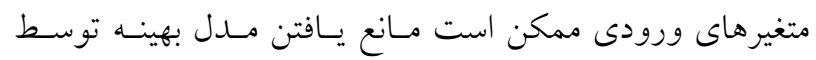

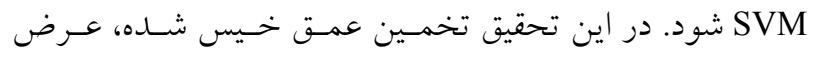

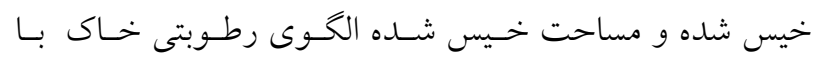

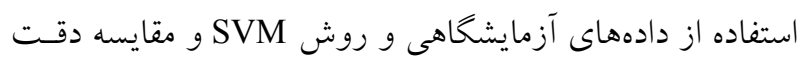

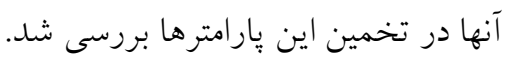

\section{مواد و روشها}

منطقه مورد مطالعه

اين يزوهش در هاييز بوسا در آزمايشخاه هيـدروليكى دانشـكده

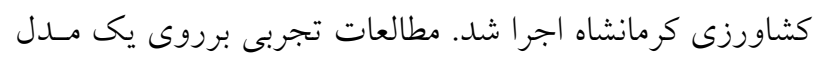

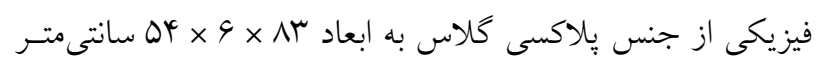

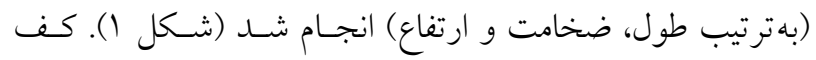

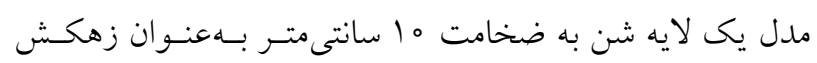

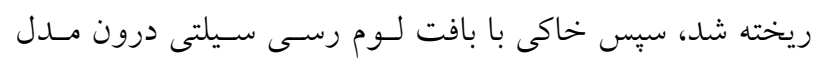

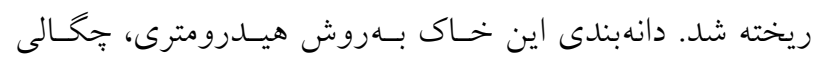

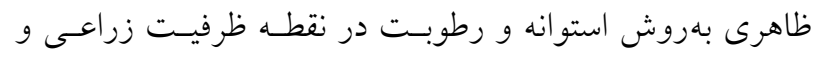

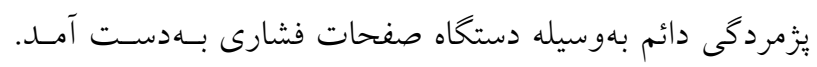
مشخصات فيزيكى خاك درون مدل در جدول (1) بـ آمده است.

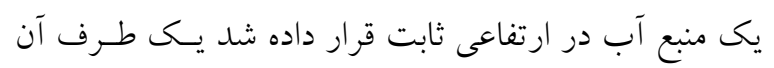

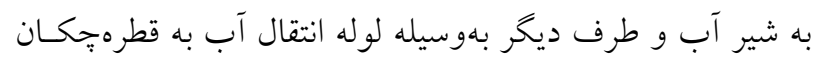

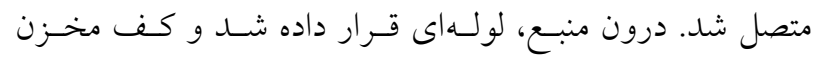

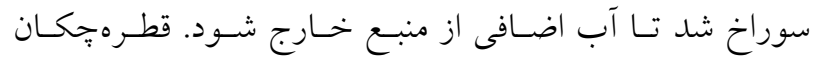

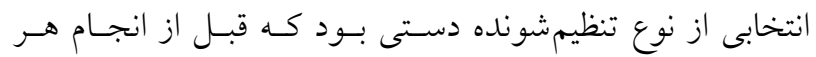

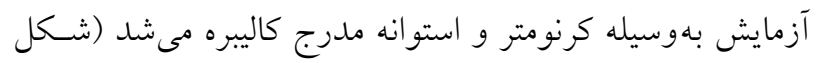

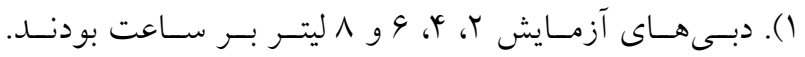

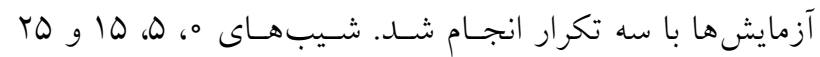

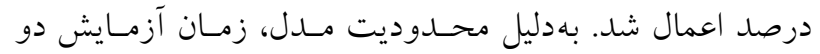

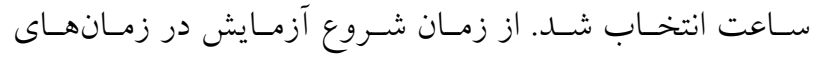

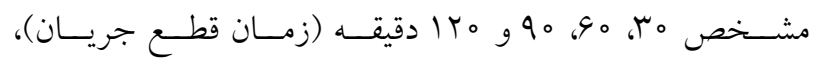

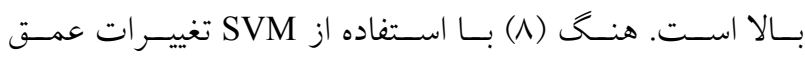

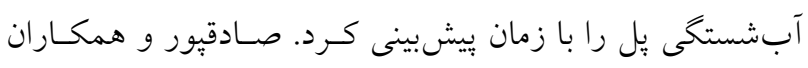
(T (I با استفاده از SVM بـه مــدلســازى رسـوب معلـق اقـدام كردند. يـو و همكـاران (ب () در مطالعـاى بــا استفاده از مـدل SVM به ييش بينى سطح رقومى سسيل در رودخانسه لـن -يانـ

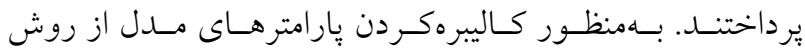

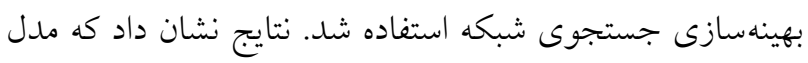

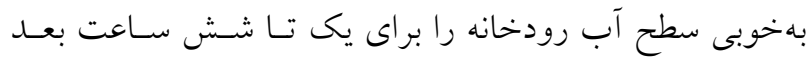

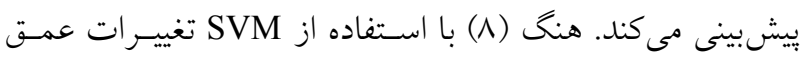

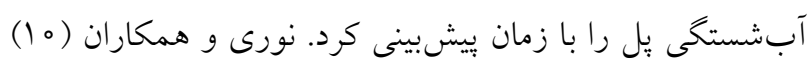

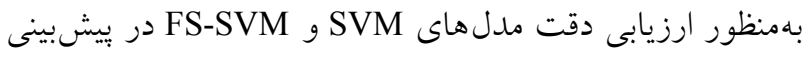
روزانه CO در شهر تهران، از شاخص ضريب همبستكى استفاده

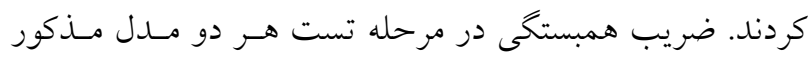

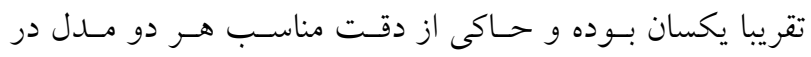

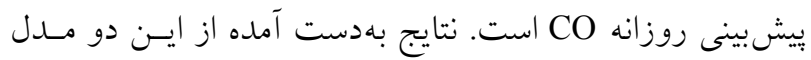

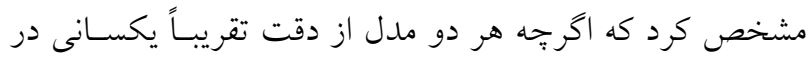

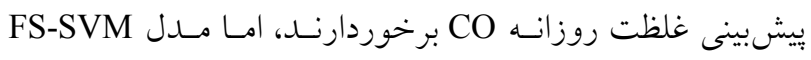

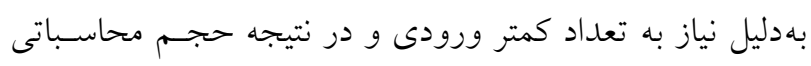

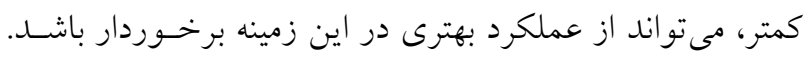

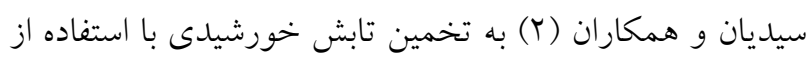

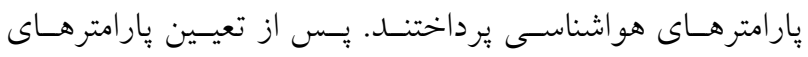

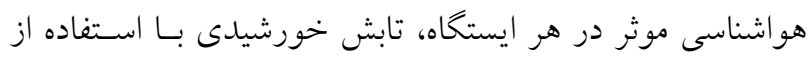

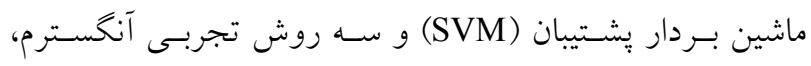

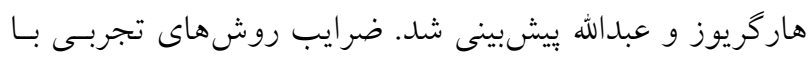

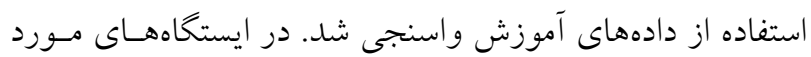

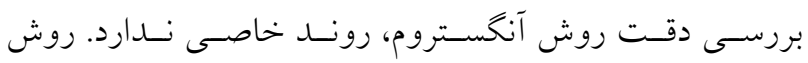

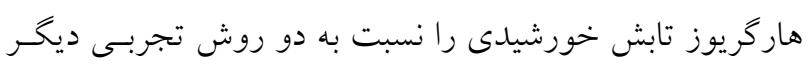

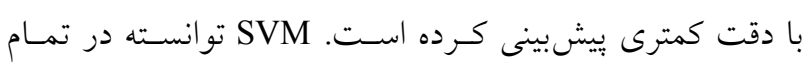

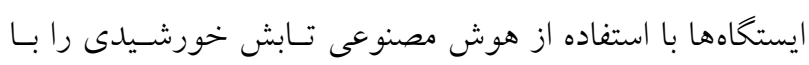

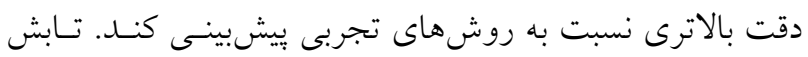

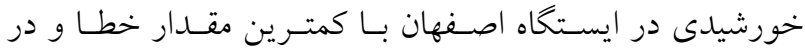
ايستخاه رامسر با بيشترين مقدار خطا بيشبينى شده است. 


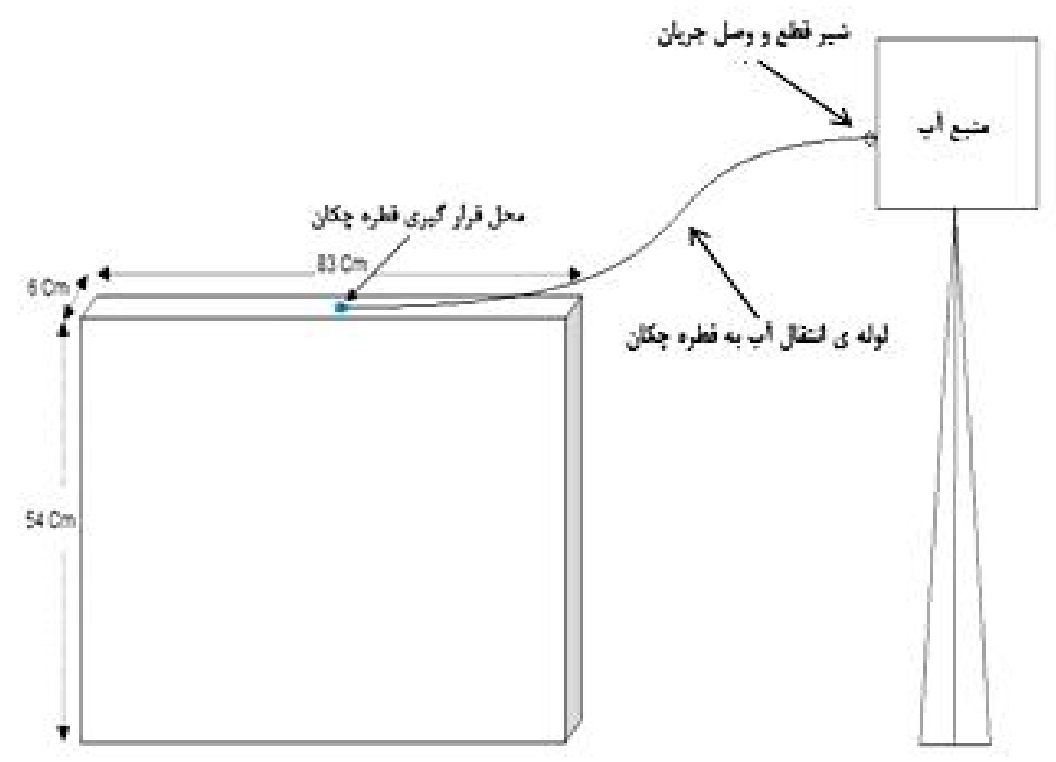

شكل 1. نماى كامل مدل و محل قرارگيرى قطرهجكان

جدول ا. ويزّى هاى فيزيكى خاك درون مدل

\begin{tabular}{|c|c|c|c|c|c|c|c|}
\hline ״جالى ظاهرى & & & & رس & سيلت & شن & عمق خاك \\
\hline$\left(\mathrm{gr} / \mathrm{cm}^{3}\right)$ & دائم & زراعى & & & $(\%)$ & & $(\mathrm{cm})$ \\
\hline $1 / \mu x$ & $0 / T 1$ & 0 M & لوم رسى سيلتى & $M T / N T$ & Or & $\mid \psi / T \Lambda$ & is \\
\hline
\end{tabular}

ماشين بردار بشتيبان (SVM)

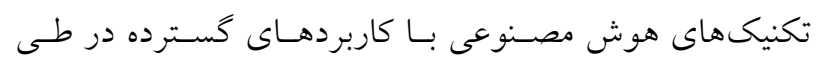

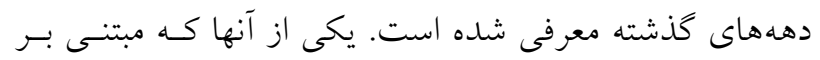

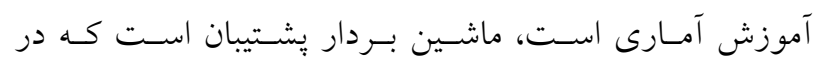

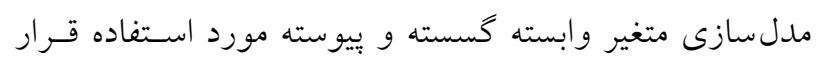

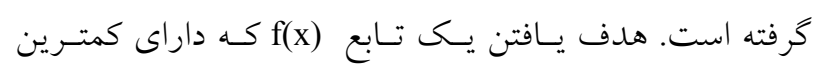

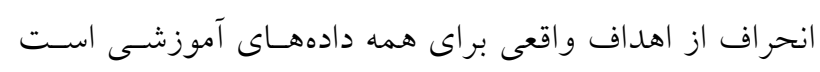

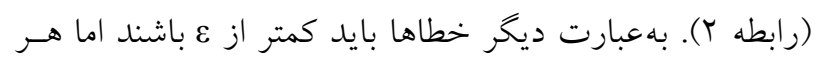

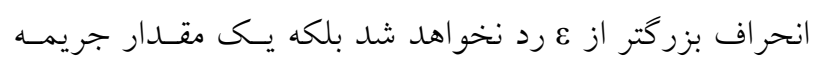
براى آن در نظر خرفته مىشود. $f(x)=\langle w, x\rangle+b, w \in X, b \in R$

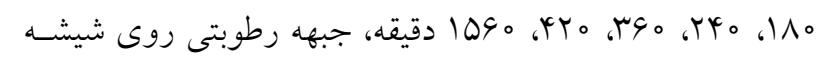
مدل كشيده شد و به كاغذ كالك منتقل شد.

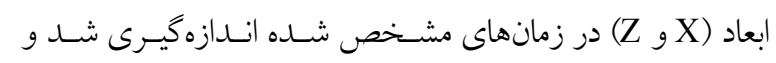

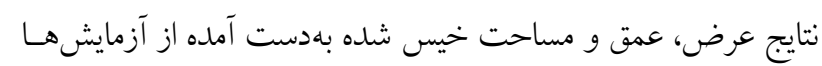
و مقادير شيهسازى شده توسط مدل SVM با هم مقايسه شد.

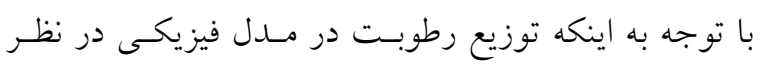

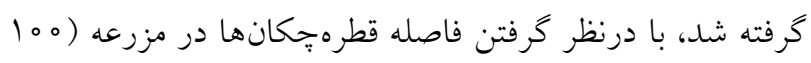

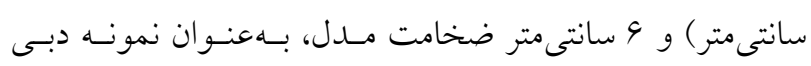
اعمال شده به خاك بهصورت رابطه (1) تعيين شد: $\mathrm{q}(\mathrm{li} / \mathrm{hr})=\frac{r(\mathrm{li} / \mathrm{hr}) \times 9 \mathrm{~cm}}{100 \mathrm{~cm}}=0 / \mathrm{rr}(\mathrm{li} / \mathrm{hr})$ 
شد. مدل SVM يار امترهاى عمق خـيس شــده، عـرض خـيس

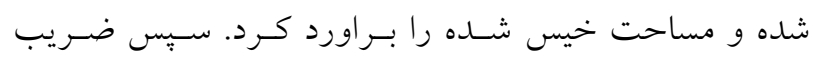

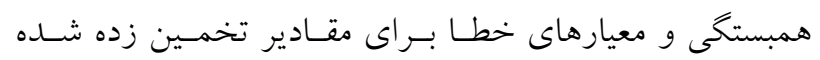
توسط SVM و مقادير واقعى اندازهيرى شده، محاسبه شد.

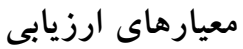

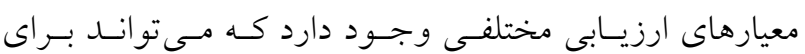
ارزيابى دقت مدلهاى هيـدرولوزيكى و هيـدروليكى اسـتفاده

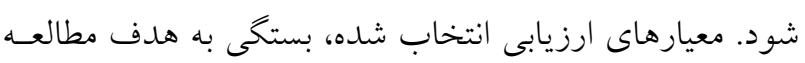

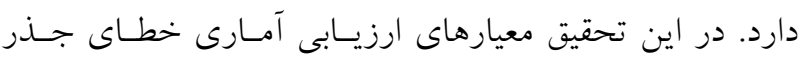

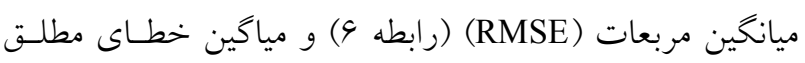

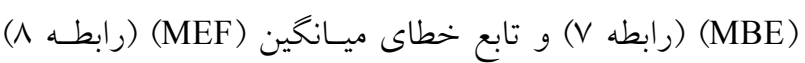
جهت مقايسه و انتخاب بهترين مدل استفاده شد.

RMSE $=\sqrt{\frac{\sum_{i=1}^{i=n}\left(A_{i}-B_{i}\right)^{r}}{n}}$

MBE $=\frac{\sum_{i=1}^{\mathrm{i}=n}\left(A_{i}-B_{i}\right)}{n}$

$\mathrm{MEF}=\frac{1}{\mathrm{n}} \sum_{\mathrm{i}=1}^{\mathrm{i}=\mathrm{n}}\left(\frac{\left|\mathrm{B}_{\mathrm{i}}-\mathrm{A}_{\mathrm{i}}\right|}{\max \left(\mathrm{B}_{\mathrm{i}}\right)-\min \left(\mathrm{B}_{\mathrm{i}}\right)}\right) \times 10$

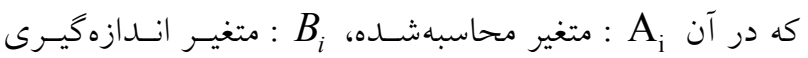
شده و n: تعداد مشاهدات است.

مقادير مثبت MBE نشان مىدهد مدل، بِارامتر را بيشـتر از مقدار واقعى و مقادير منفى، نشـان مسيدهـــ مــل، بـارامتر را كمتر از مقدار واقعى ييش بينى مى كند، همجنين MEF مقــادير

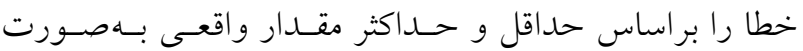
درصد بيان مى كند.

\section{نتايج و بحث}

خاك مورد آزمايش داراى بافت لوم رسى سيلتى بود. بيشـترين

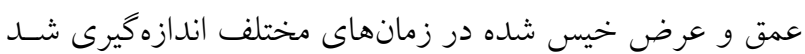

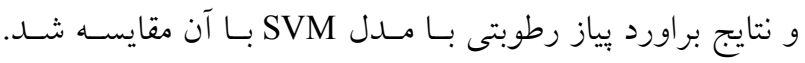

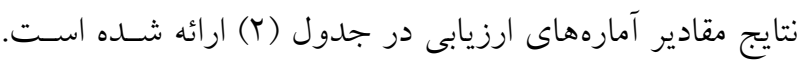

حداقل كردن W مى Wو اند بهعنوان يكى مسـئله بهينـهــازى بـا

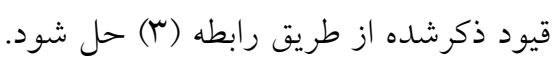

$\operatorname{Minimize} \frac{1}{r} w \|^{r}+C \sum_{i=1}^{l}\left(\xi_{i}+\xi_{i}^{*}\right)$

تابع خطاى مذكور لازم است كه با توجه بـه محسـوديتهــاى رابطه (广) كمينه شود.

$\left|\mathrm{y}_{\mathrm{i}}-<\mathrm{W}^{\mathrm{T}} \phi\left(\mathrm{X}_{\mathrm{i}}\right)>-\mathrm{b}\right| \leq \varepsilon+\xi_{\mathrm{i}}$

$\xi_{\mathrm{i}} \geq 0, \xi_{\mathrm{i}}^{0} \geq 0 \quad, \quad \mathrm{i}=1, \ldots, \mathrm{N}$

كه در اين روابط C ثابت گنجـايش، WT بـردار ضـرايب، WT

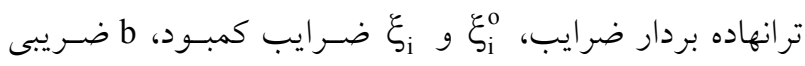

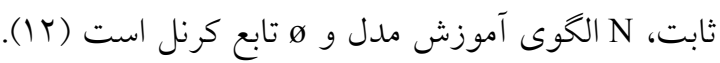

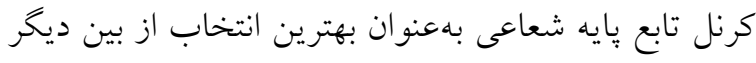

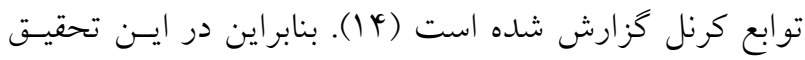
تابع مذكور كه توسط $\gamma$ در رابطه (ه) تعريف شده است، بهكار كرفته شد.

$K\left(x_{i}, x\right)=\exp \left(-\gamma|x i-x|^{\Upsilon}\right)$

بدين منظور در اين تحقيق از روش جستجوى شبكهاى استفاده

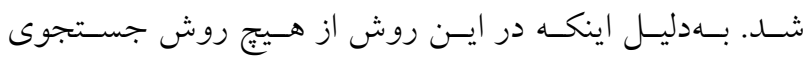

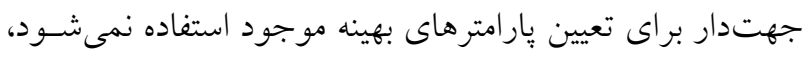

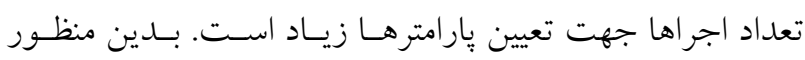
جهت كـاهش تعـداد اجراهـا ايـن روش در دو مرحلـه انجـام

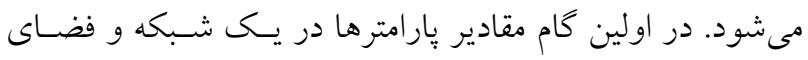
بزرگتر و با دقت كمتر بررسى مى شود، يس إز تعيسين بهتـرين

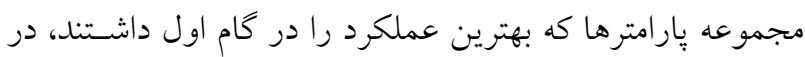

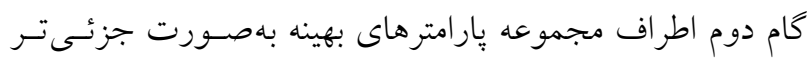

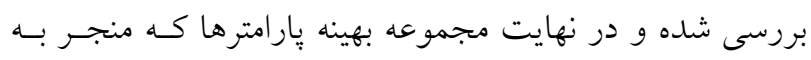
بهترين عملكرد مدل مىشود، تعيين مىشود.

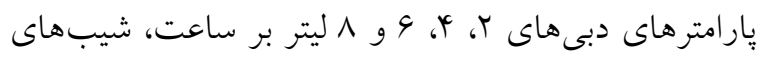

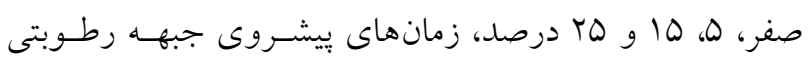
צr ساعت بهعنوان ورودى و بِارامترهاى عمـق خـيس شـــه،

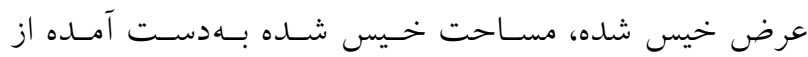
دادههاى آزمايشخاهى بهعنـوان خروجسى بـه مــل SVM داده 
جدول r. شاخصهاى آمارى براى عمق، عرض و مساحت خيس شده تخمينى

\begin{tabular}{|c|c|c|c|c|c|}
\hline MBE & MEF & RMSE & $\mathrm{R}^{2}$ & & \\
\hline 。 & $0 / 0 Y 9$ & $0 / 14$ & $0 / 91$ & آموزش & \multirow{2}{*}{ عمق خيس شده } \\
\hline$-0 / 0 \mu$ & $\circ / \circ \Delta \circ$ & $O / V Y$ & $0 / 99$ & ارزيابى & \\
\hline 。 & $0 / 0 Y Y$ & $1 / 0 Y$ & $0 / 91$ & آموزش & \multirow{2}{*}{ عرض خيس شده } \\
\hline - & $\circ / 0 \uparrow \wedge$ & $1 / T r$ & $0 / 99$ & ارزيابى & \\
\hline $10 / 0$ & $0 / 0 P^{f}$ & $\Delta \Delta / \Delta \Delta$ & $0 / 94$ & آموزش & \multirow{2}{*}{ مساحتخيس شده } \\
\hline$-Y / \circ \varphi$ & $\circ / 0 V$ & $\Delta \Lambda / G V$ & $0 / 9 T$ & ارزيابى & \\
\hline
\end{tabular}

خيس شده را با خطاى بيشترى شبيهسازى كرده است. بنـابراين مدل SVM مقادير عمق و عرض خيس شده را بهتر از مساحت خيس شده شبيهسازى كرده است. با توجه به نتايج شبيهسازى مشخصات بياز رطوبتى با مدل SVM در اين يزوهش، در بيشبينى خصوصيات بياز رطوبتى، بسـيار خوب بود. اين مسئله را مىتوان از محدوده تغييـرات مقـادير

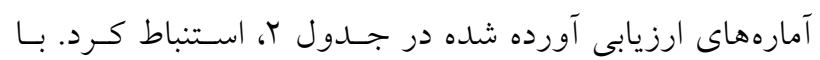
توجه به مقادير آمارههاى جدول (Y)، مقادير عمق خيس شــده

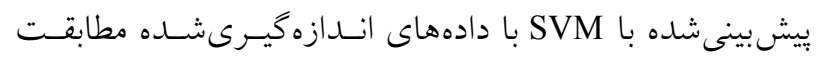
بيشترى داشت. نتايج بـهدسـت آمـده بــا مطالعـات عبـدالهى سياهكلرودى (r) و سينگ و همكاران (r| (I) همخوانى داشت. شكل (Y r Y Y) ، مقادير براورد شده عمق، عرض و مساحت خيس شده بياز رطـوبتى بـا روش SVM را نسـبت بــه مقـادير

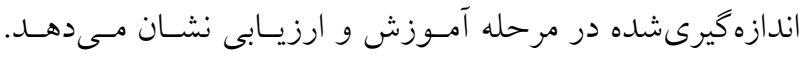
شكل (T)، مقادير بيشبينى شده عمق خيس شده يياز رطوبتى را نشان مىدهد. در شـكل (Y)، محسور افقـى عمـق خـيس شـده مشاهدهاى (دادههـاى آزمايشـخاهى) و محسور عمـودى، عمـق خيس شده تخمينى توسط مدل SVM را نشان مسىدهـد. مركـز نقاط در اطراف خط ا ا: اثبات كننده اختلاف اندك بين مقـادير يميشبينى شده با روش SVM و مقادير اندازه گيرى شده است.

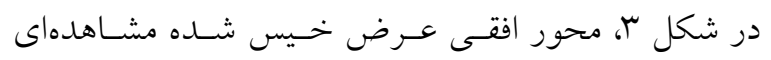

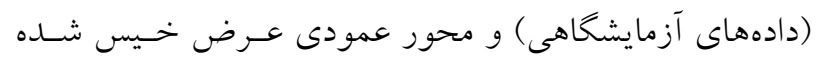
تخمينى توسط مدل SVM را نشان مسىدهـــ. مركـز نقـاط در
مـــ SVM در مرحلـه آمـوزش از له درصـــ دادههــا و در مرحله ارزيابى از هب درصــ دادههـا اسـتفاده كــده و در هـر مرحله عمق، عرض و مساحت خيس شده را براورد كرد. با توجه به جدول (Y)، مقادير R2 براى يارامترهـاى عمـق

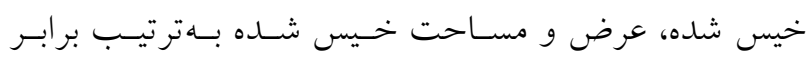

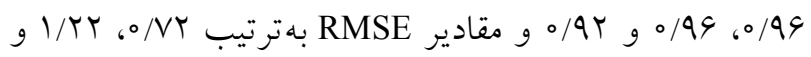

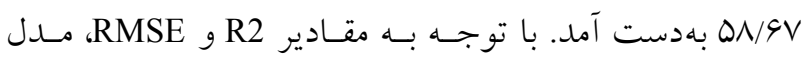
عمق خيس شده را با دقت بيشترى براورد كرده اسـت. مقايسه مقادير RMSE بـا مقــادير RMSE حاصسله در مطالعـه. خانمحمدى و همكاران ( (1) (RMSE) براى قطـر خـيس شـده

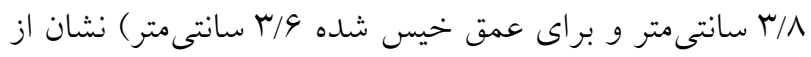
قابليـت بـالاى مــل SVM در ايسن تحقيـق نسـبت بـه مــدل هايدروس در تحقيق ايشان دارد. با توجه به مقادير MBE، مدل يارامترهـاى عـرض و سـطح خيس شده را كمتر از مقدار واقعى شبيهسازى كـرده اسـت. بــا توجه به مقدار MBE، در مـدل SVM يـارامتر عمـق و عـرض خيس شده سه درصد كمتر از مقدار واقعى تخمين زده و سطح خيس شده را Y/O درصد كمتر از ميزان واقعسى بـراورد كـرده

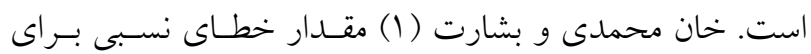

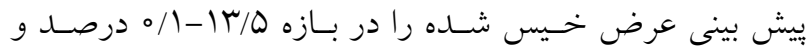
مقدار خطاى نسـبى در محاسـبه عمـق جبهـه رطسوبتى را بـين 1/N/9-ه درصد بيان كردند، مقادير بهدست آمده در ايسن تحقيـق كمتر از نتايج حاصله توسط خان محمدى و بشـارت (1) بـود. همجنين با توجه بـه مقـادير MEF، مــد SVM يـار امتر سـطح 


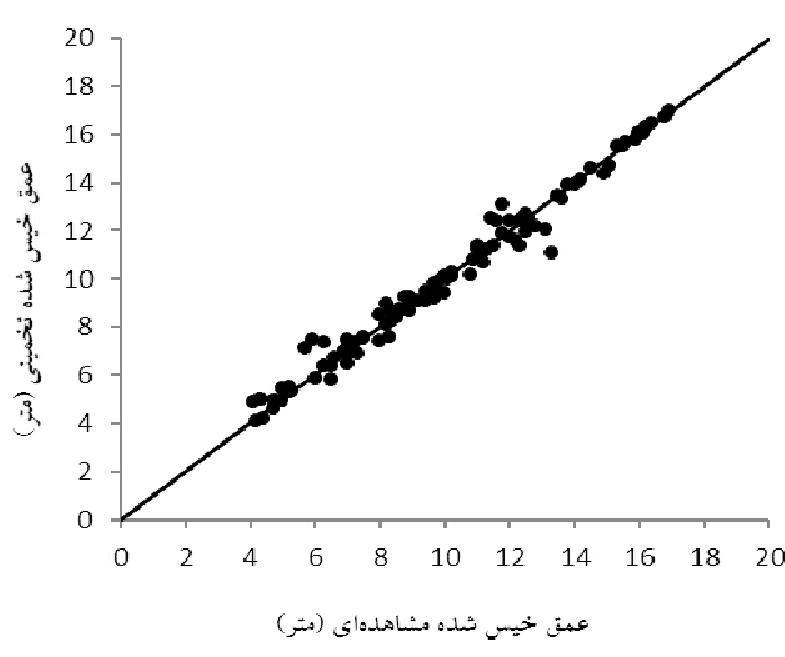

(ب)

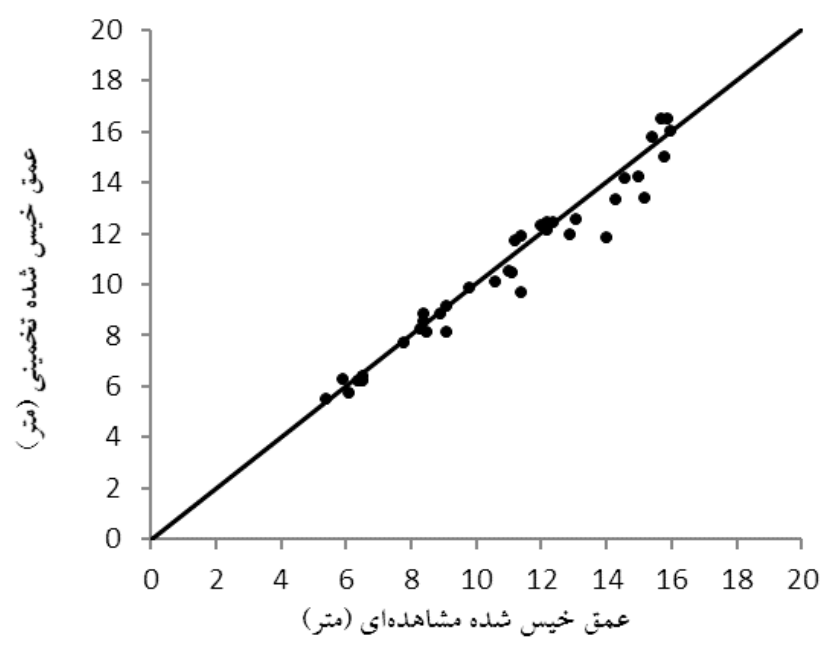

(الف)

شكل r. مقادير تخمينى و اندازهيرى شده حداكثر عمق خيس شده: الف) مرحله آموزش و ب) مرحله ارزيابى

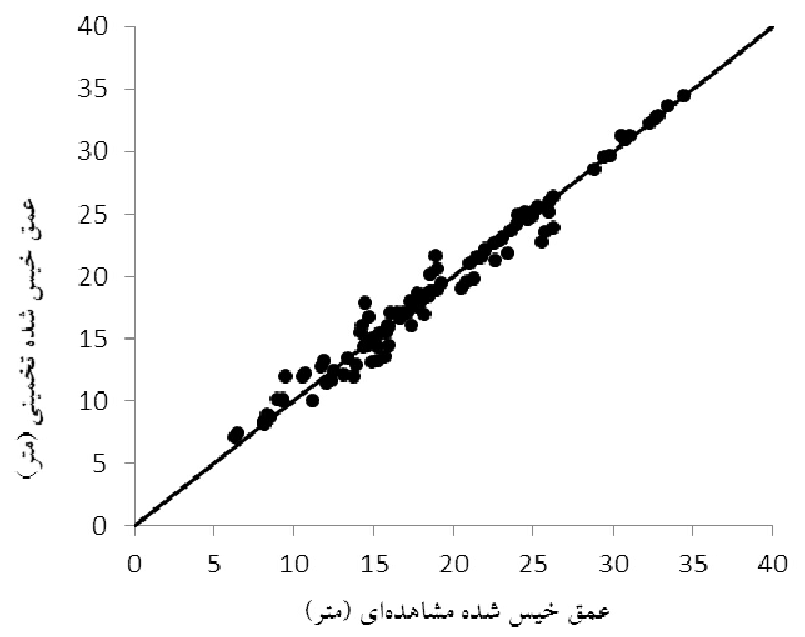

(ب)

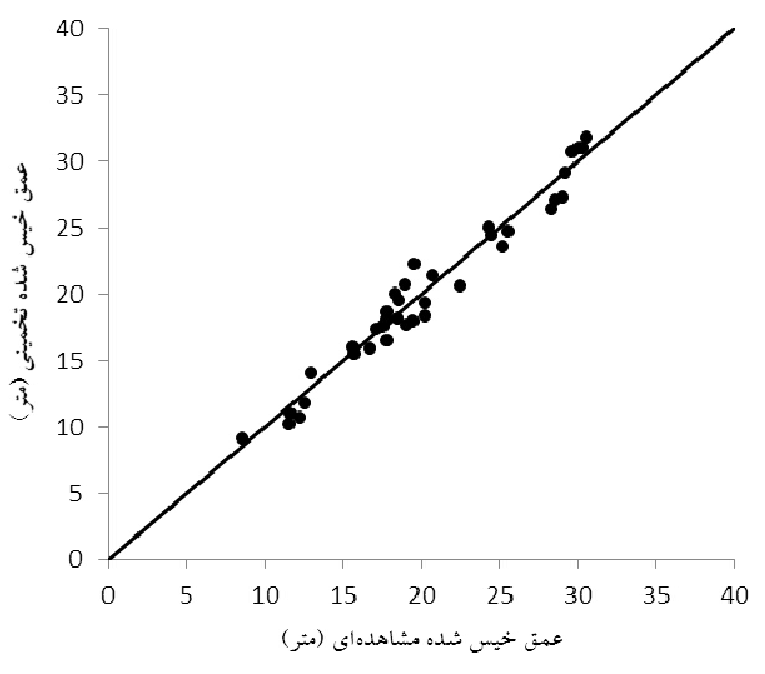

(الف)

شكل r. مقادير تخمينى و اندازهيرى شده حداكثر عرض خيس شده: الف) مرحله آموزش و ب) مرحله ارزيابى (ب)

تخمينى توسط مـدل SVM را نشـان مسىدهـد. همـانطوركـه

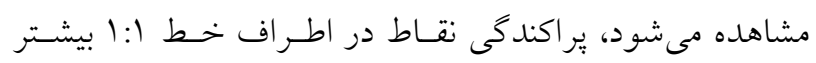

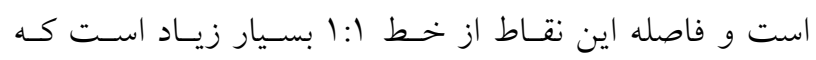

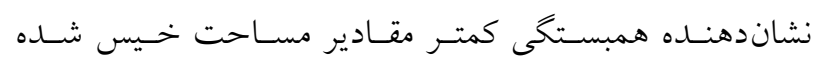

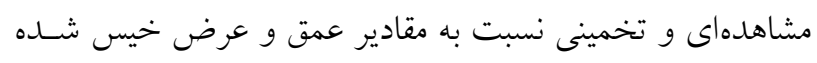

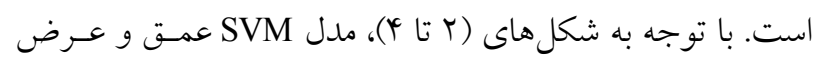

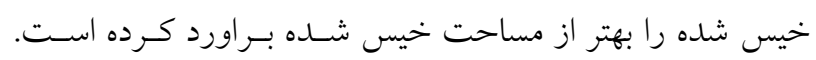

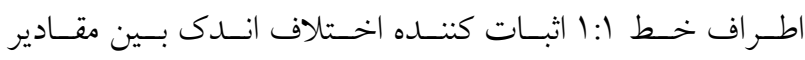
بيش بينى شده با روش SVM و مقادير انـدازهذيـرى شــده اسـت.

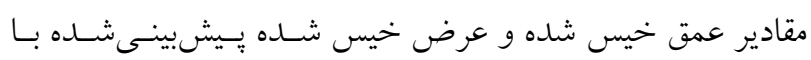

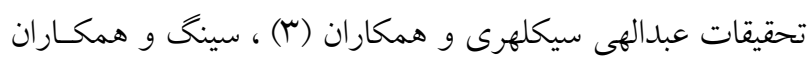

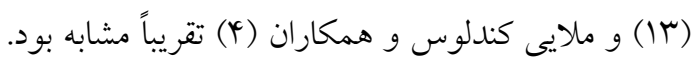

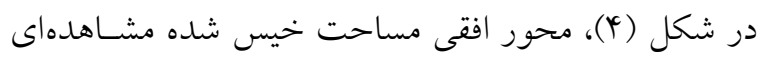

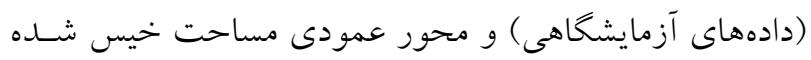




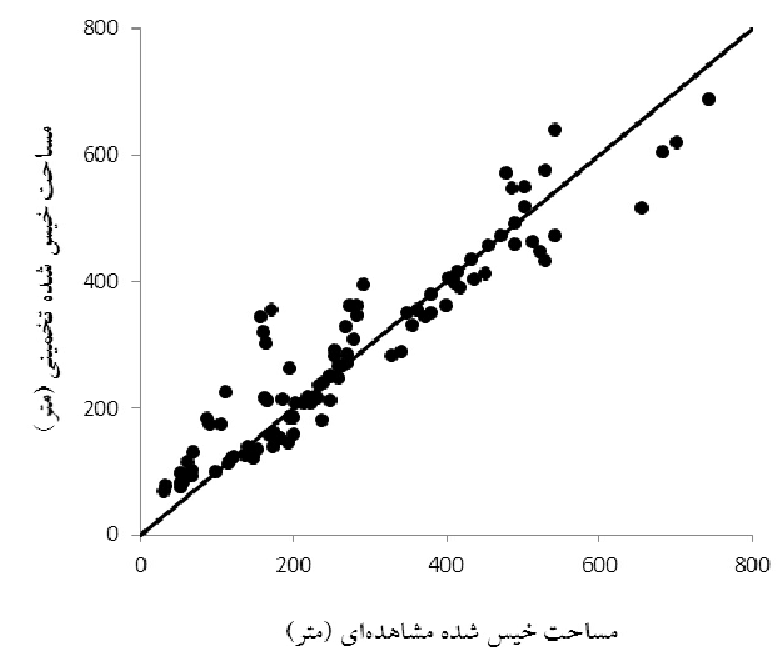

(ب)

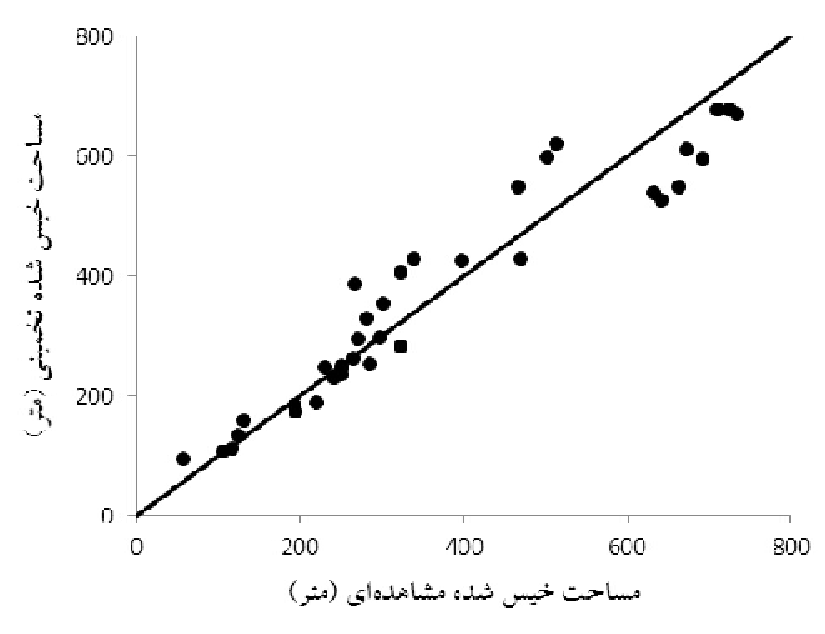

(الف)

شكل f. مقادير تخمينى و اندازهيرى شده حداكثر مساحت خيس شده: الف) مرحله آموزش و ب) مرحله ارزيابى

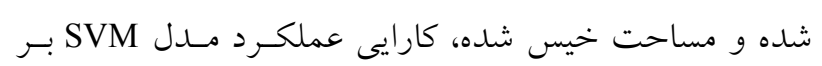

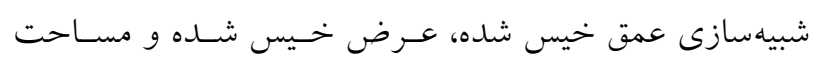

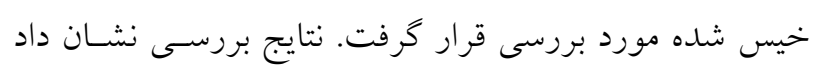

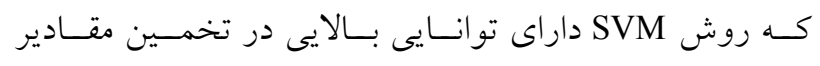

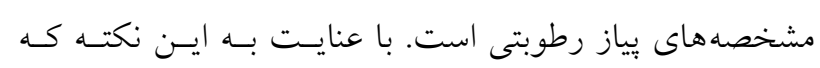

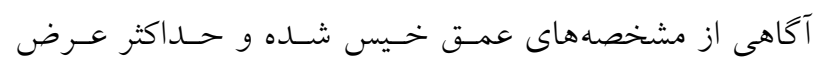

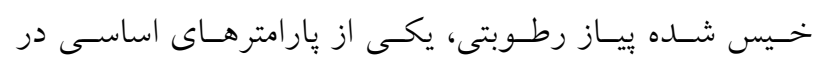

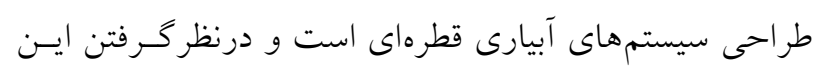

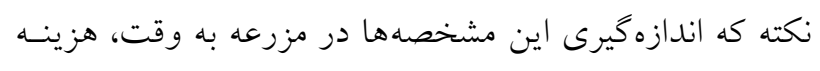

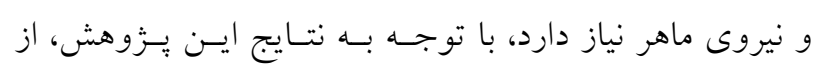
روابط و توابع بسط داده شده جهت تخمين مشخصه هاى بياز رطوبتى، مىتوان در زمان طراحى سود جست.
با توجه به نتـايج بـهدسـت آمـده، مــل SVM داراى قابليـت

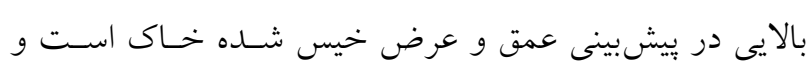

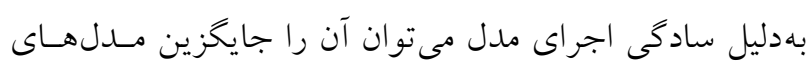

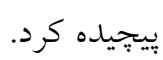

\section{نتيجه گيرى}

بهدليل اهميت بــراورد بيـاز رطـوبتى در سيسـتمهـاى آبيـارى

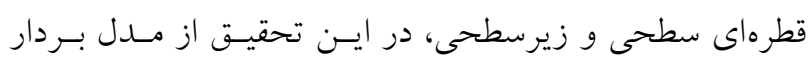

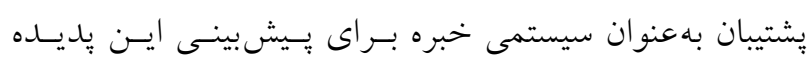

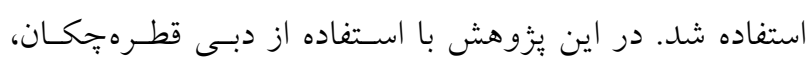

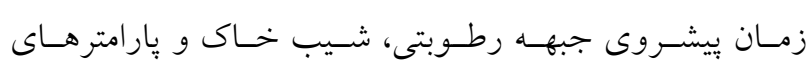

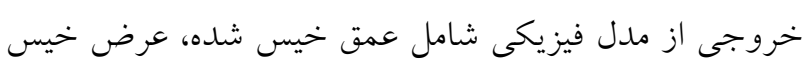

منابع مورد استفاده

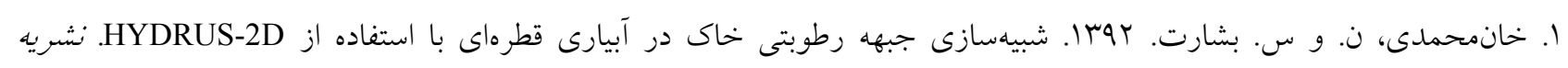

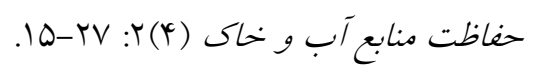

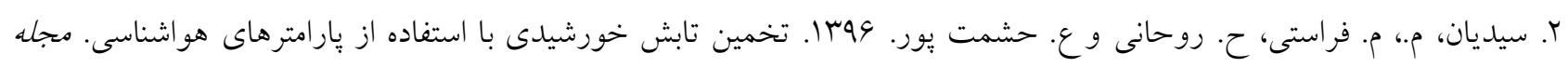

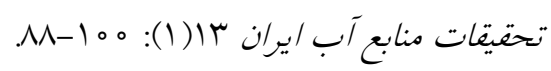

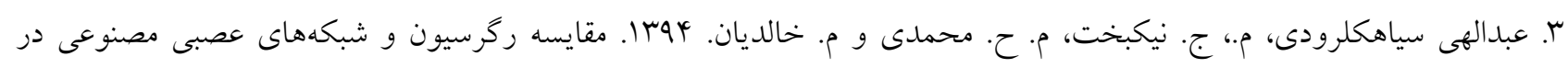




$$
\begin{aligned}
& \text { برآورد ابعاد بياز رطوبتى با آب معمولى و مغناطيسى. نشريه آبيارى و زهكشى 9(1) (1): IVo-IV9. }
\end{aligned}
$$

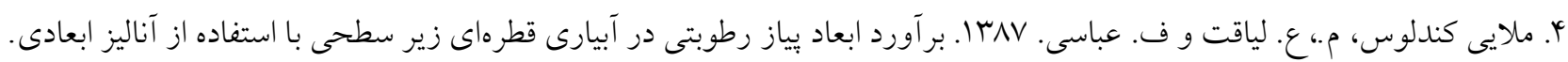

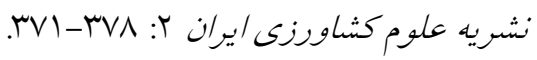

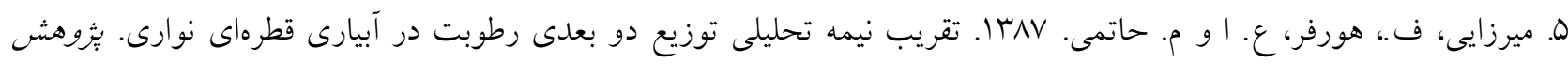

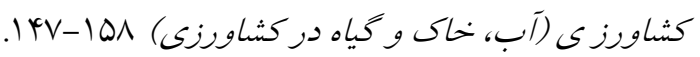

$$
\begin{aligned}
& \text { 9. نصيرى، ش.، ع. نشاط و م. كهنوجى. هوبا. تعيين معادلههاى تجربى برآورد ابعاد بياز رطوبتى تحت آبيارى قطرهاى در خاكهاى } \\
& \text { متوسط شنى (مطالعه موردى دشت قائم آباد، كرمان). † (9): }
\end{aligned}
$$

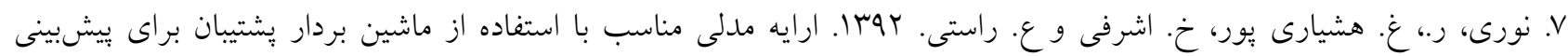

$$
\begin{aligned}
& \text { غلظت روزانه مونو كسيدكربن در هواى شهر تهران. }
\end{aligned}
$$

8. Hong, J. H., M. K. Goyal, Y. M. Chiew and L. H. C. Chua. 2012. Predicting time-dependent pier scour depth with support vector regression. Journal of Hydrology 468-469. 241-248.

9. Malek, K. and R. T. Peters. 2011. Wetting pattern models for drip irrigation: new empirical model. Journal of Irrigation and Drainage 137(8): 530-537.

10. Noori, R., A. Karbassi, A. Farokhnia and M. Dehghani. 2009. Predicting the longitudinal dispersion coefficient using support vector machine and adaptive neuro-fuzzy inference system techniques. Environmental Engineering Science 26(10): 1503-1510.

11. Noori, R., A. R. Karbassi, A. Moghaddamnia, D. Han, M. H. Zokaei-Ashtiani and A. Farokhnia. 2011. Assessment of input variables determination on the SVM model performance using PCA, Gamma test and forward selection techniques for monthly stream flow prediction. Journal of Hydrology 401(3-4): 177-189.

12. Sadeghpour Haji, M., S. A. Mirbagheri, A. H. Javid, M. Khezri and G. D. Najafpour. 2014. Suspended sediment modelling by SVM and wavelet. Građevinar 66(3): 211-223.

13. Singh, D. K., T. B. S. Rajput, D. K. Singh, H. S. Sikarwar, R. N. Sahoo and T. Ahmad. 2006. Simulation of soil wetting pattern with subsurface drip irrigation from line source. Agricultural Water Management 83: 1-2.

14. Yu, P. S., S. T. Chen and I. F. Chang. 2006. Support vector regression for real-time flood stage forecasting. Hydrology 328: 704-716.

15. Vapnik, V. N. 1998. Statistical Learning Theory. Wiley, New York. 


\title{
Applicability of Support Vector Machine in Simulating Wetting Pattern under Trickle Irrigation
}

\author{
Z. Heidari ${ }^{1}$, M. Farasati ${ }^{1,2 *}$ and R. Ghobadian ${ }^{1}$
}

(Received: March 5-2016 ; Accepted: October 22-2017)

\begin{abstract}
To design cost-effective and efficient drip irrigation systems, it is necessary to know the vertical and horizontal advance of the wetting front under the point source; also, the proper management of drip irrigation systems requires an awareness of the soil water distribution. Many factors influence wetting pattern dimensions, including discharge, land slope, irrigation time and soil texture. The purpose of this study was to investigate the applicability of the support vector machine in simulating the wetting pattern under trickle irrigation. After preparing a physical model made of Plexiglas with specific dimensions and filled with silty clay loam soils, experiments were conducted in the irrigation laboratory of Razi University, Iran, with emitters of 2, 4, 6 and 8 1/hour discharge during the irrigation intervals of 2 hours and 24 hours redistribution and $0,5,15$ and $20 \%$ slope with three replications. In this study, the statistical indicators $\mathrm{R}^{2}$, RMSE, MBE and MEF were used. $\mathrm{R}^{2}$ values for the wet depth, width and area were $0.96,0.96$ and 0.92 , respectively. Regarding the MBE value, the SVM model estimated the wet width and depth parameters to be $3 \%$ less than the actual value, and simulated the wet area $2.04 \%$ less than the real value. Also, according to the MEF and RMSE values, the SVM model simulated the wet area parameter with more error. Overall, the results showed that the SVM model had a high ability to estimate the wetting pattern parameters.
\end{abstract}

Keywords: Drip irrigation, Wet area, Wet depth, Wet width, Wet surface

1. Department of Water Engineering, College of Agriculture, Razi University, Kermanshah, Iran.

2. Department of Range and Watershed Management, College of Agricultural, Gonbad Kavous University, Gonbad, Iran.

*: Corresponding Author, Email: farasati2760@gmail.com 